\title{
A queda da máscara pelo não dito no discurso linguístico: Pacheco, segundo o ato perlocutivo de Fradique Mendes
}

\author{
Nelyse A. Melro Salzedas \\ Universidade Estadual Paulista "Júlio de Mesquita Filho" (UNESP), Bauru, São Paulo, Brasil \\ nelysesalzedas@yahoo.com.br \\ http://orcid.org/0000-0002-5859-6391 \\ Rivaldo Alfredo Paccola \\ Universidade Federal dos Vales do Jequitinhonha e Mucuri (UFVJM), \\ Diamantina, Minas Gerais, Brasil \\ rivapaccola@terra.com.br \\ http://orcid.org/0000-0002-2792-2748
}

DOI: http://dx.doi.org/10.21165/el.v47i3.1976

\begin{abstract}
Resumo
A estrutura de um texto direciona a sua leitura, pois ele é uma trama cujos fios se laçam e vão formando um desenho. A carta Ao Sr. E. Mollinet, na Correspondência de Fradique Mendes, de Eça de Queiroz (s/d), instiga o leitor a procurar teóricos e teorias. A nossa escolha recaiu em Austin (1962) e Searle (1969). Suas obras How to do things with words e Speech acts, respectivamente, foram os olhares e a teoria direcionados para a leitura da referida carta, que nos permitiu desmascará-la pelo não dito do discurso linguístico, segundo a Teoria dos Atos de Fala. O texto de Austin consta de doze leituras que enfatizam os verbos performativos e constatativos; os atos locucionários e perlocucionários presentes na linguagem ordinária, fundamentados na filosofia britânica analítica. Parece-nos ser a ideia de que a linguagem deve ser tratada essencialmente como fonte de ação e não representação da realidade. "Eu casualmente conheci Pacheco", é o texto gerador da carta de Fradique Mendes, resposta ao Sr. E. Mollinet. Aí começam os primeiros traços da máscara de Pacheco, tão bem estruturada pelos atos performativos. Segundo Searle (1969, p. 16), "tomar o texto como uma mensagem, é tomá-lo como um texto produzido ou emitido.".
\end{abstract}

Palavras-chave: atos de fala; carta Ao Sr. E. Mollinet; linguagem.

The fall of the mask by the unsaid in the linguistic discourse: Pacheco, according to the perlocutive act of Fradique Mendes

\begin{abstract}
The structure of a text directs its reading because it is a plot which threads are looped and forming a drawing. The letter To Mr. E. Mollinet, in the Correspondence of Fradique Mendes, by Eça de Queiroz (s/d), instigates the reader to look for theorists and theories. Our choice fell on Austin (1962) and Searle (1969). Their works, How to do things with words and Speech Acts, respectively, were the looks and the theory used to read the letter that enabled us to unmask it by the non-spoken language discourse, according to The Theory of Speech Acts. Austin's text consists of twelve readings that emphasize performative and constative verbs; the locutionary and perlocutionary acts present in ordinary language, grounded in analytical British philosophy. It seems to us to be the idea that language should be treated essentially as a source of action and not representation of reality. "I casually met Pacheco", is the source of Fradique Mendes' letter, answer to Mr. E. Mollinet. Thus the first traces of Pacheco's mask begin, so well-structured by
\end{abstract}


the performative acts. According to Searle (1969, p. 16), "to take the text as a message is to take it as a text produced or issued."

Keywords: language; letter To Mr. E. Mollinet; speech acts.

\section{O não dito no discurso linguístico}

A pesquisa para a construção deste texto focou a produção e a leitura da "carta Ao Sr. E. Mollinet", de Eça de Queiroz (s/d). Para tal, recorremos aos textos clássicos dos teóricos Austin e Searle. Na carta, destacamos uma pluralidade discursiva, suas tensões, sua formação ideológica, sua articulação, sua tipologia, a interação locutor-receptor. Austin (1962), Searle (1969) e Fradique Mendes (Eça de Queiroz) constituem a receita linguística a ser costurada através de pontos e laçadas neste texto. As laçadas constroem os pontos para desenhar o texto e a teoria de Austin foi a linha utilizada junto a Searle para ler o texto de Fradique Mendes, carta Ao Sr. E. Mollinet.

A contribuição de Austin, segundo Souza Filho (1990), é o ponto central da concepção daquele autor junto à filosofia da linguagem. Assim, parece-nos ser a ideia de que a linguagem deve ser tratada essencialmente como uma fonte de ação e não representação da realidade. Na interpretação de Souza Filho (1990, p. 10):

Neste método de análise, a necessidade de se levar em conta o contexto de uso das expressões e os elementos constitutivos deste contexto indica claramente que a linguagem não deve ser considerada em abstrato, em sua estrutura formal apenas, mas sempre em relação a uma situação em que faz sentido o uso de tal expressão. Desta forma superamse as barreiras entre linguagem e mundo, entre o sistema de signos sintaticamente ordenados e a realidade externa a ser representada.

Em How to do things with words, Austin (1962) explora, através de doze lectures, o sistema de verbos performativos e constatativos. Para esta análise, selecionamos: Lecture I "performativos"; Lecture VI "performativos explícitos"; Lecture VII "verbos performativos explícitos"; Lecture VIII "atos locucionários, ilocucionários e perlocucionários"; Lecture XI "declarações, performativos e força ilocucionária"; Lecture $X I I$ "classe de força ilocucionária".

$\mathrm{Na}$ Leitura I, Austin trabalha com os verbos performativos e constatativos, explicando que o primeiro refere-se à derivação do inglês "to perform", do substantivo "ação". Nesse sentido, ao se emitir um proferimento performativo realiza-se uma ação, não sendo, por isso mesmo, considerado um mero equivalente ao ato de dizer algo. Nas demais leituras, Austin (1962) dedica-se ao desdobramento do verbo performativo. Embora ressalte que, em uma sentença, as duas formas podem ser usadas em diferentes ocasiões de proferimentos, o traço do performativo caracteriza-se pelo verbo no presente do indicativo, na primeira pessoa do singular, da voz ativa: exemplificando, "Eu casualmente conheci Pacheco", na carta Ao Sr. E. Mollinet (QUEIROZ, s/d, p. 1064). Isso contrasta com o ponto de vista dos proferimentos constatativos que se referem meramente a declarações, por exemplo, "Pacheco não fez durante os longos meses de gerência 'absolutamente nada' [...]" (Ibid., p. 1066).

Trazemos a contribuição de Searle (1969) na qual sua primeira indagação referese ao relacionamento das palavras com o mundo e a posição de um falante frente a um ouvinte (na carta em análise: Fradique e Mollinet), que justifica o estudo dos atos de fala e foi retirada do texto de abertura Methods and scope: 
A razão para concentrar-se no estudo de atos de fala é simplesmente esta: toda comunicação linguística não é, como geralmente se supõe, o símbolo, palavra ou sentença, mas antes a produção ou emissão do símbolo ou palavra ou sentença no desempenho do ato de fala. Tomar o texto como uma mensagem é tomá-lo como um texto produzido ou emitido. (SEARLE, 1969, p. 16, tradução de Besma Massad) ${ }^{1}$. Mollinet.

Tais considerações são os instrumentos linguísticos para a análise da carta ao Sr.

\section{A produção da máscara pelos atos de fala}

O terceiro foco deste trabalho é a carta Ao Sr. E. Mollinet. Por que o interesse nessa produção textual? Primeiro, é uma carta resposta da qual o leitor não tem o questionamento que a gerou, a não ser o seu primeiro enunciado, através do discurso indireto, seguido de um outro ato de fala que gerou toda a narrativa à resposta ao Sr. Mollinet: "Eu casualmente conheci Pacheco" (QUEIROZ, s/d, p. 1064), o que nos instigou à leitura dos textos de Austin e Searle: o uso e a posição do advérbio "casualmente", como ocorre no texto teórico de Austin, "Na linguagem escrita - e, até mesmo, em certos casos, na linguagem falada, embora nesta isto não seja necessário utilizamos advérbios e expressões adverbiais e certos torneados linguísticos. (Id.)"2 (AUSTIN, 1962, p. 74-75). Para o performativo explícito, Austin (1962, p. 73) ressalva que:

A fórmula performativa explícita, além disso, é apenas o último e o mais eficaz recurso linguístico, dentre muitos que sempre foram usados com maior ou menor êxito para desempenhar a mesma função (assim como a padronização foi o recurso mais bemsucedido para se desenvolver a precisão da fala).

Considere por um momento alguns desses outros dispositivos mais primitivos na fala, alguns dos papéis que podem (embora, é claro, não sem mudança ou perda, como veremos) ser assumidos pelo dispositivo do performativo explícito. (Id.) (AUSTIN, 1962, p. 73$)^{3}$.

A teoria de Austin direciona nosso olhar para o enunciado gerado pelo advérbio "casualmente", uma vez que, no último parágrafo da carta ao Sr. Mollinet, Fradique "viu" o que faz o contraditório com "casualmente", construído com uma série de verbos

\footnotetext{
${ }^{1}$ The reason for concentrating on the study of acts is simply this: all linguistic communication involves linguistic acts. The unit of linguistic communication is not, as has generally been supposed, the symbol, word or sentence, or even the token of the symbol, word or sentence, but rather the production or issuance of the symbol or word or sentence in the performance of the speech act. To take the token as a message is to take it as a produced or issued token. More precisely, the production or issuance of a sentence token under certain conditions is a speech act, and speech acts (of certain kinds to be explained later) are the basic or minimal units of linguistic communication.

${ }^{2}$ But in written language - and even, to some extent, in spoken language, though there they are not so necessary - we rely on adverbs, adverbial phrases, or turns of phrase.

${ }^{3}$ The explicit performative formula, moreover, is only the last and "most successful" of numerous speech devices which have always been used with greater or less success to perform the same function (just as measurement or standardization was the most successful device ever invented for developing precision of speech).

Consider for a moment some of these other more primitive devices in speech, some of the roles which can (though, of course, not without change or loss, as we shall see) be taken over by the device of the explicit performative.
} 
performativos: "eu encontrei"; "asseguram amigos meus"; "lamentei diante da ilustre e afável senhora"; "Eu aludi ao imenso talento de Pacheco", etc., presentes no trecho abaixo:

Meses depois da morte de Pacheco, encontrei a sua viúva, em Sintra, na casa do Dr. Videira. É uma mulher (asseguram amigos meus) de excelente inteligência e bondade. Cumprindo um dever de português, lamentei, diante da ilustre e afável senhora, a perda irreparável que era sua e da Pátria. Mas quando, comovido, aludi ao imenso talento de Pacheco, a viúva de Pacheco ergueu, num brusco espanto, os olhos que conservara baixos - e um fugidio, triste, quase apiedado sorriso arregaçou-lhe os cantos da boca pálida... Eterno desacordo dos destinos humanos! Aquela mediana senhora nunca compreendera aquele imenso talento! Creia-me, meu caro Sr. Mollinet, seu dedicado - FRADIQUE. (QUEIROZ, s/d, p. 1068).

Em outras passagens da carta (QUEIROZ, s/d, p. 1064), o advérbio "amargamente" amplia e aprofunda a função do verbo em "cuja morte está sendo tão vasta e amargamente carpida nos jornais de Portugal"; como "sonoras e reverentes lágrimas"; "talento, calado e recolhido". Ainda, o processo enunciativo da carta recebe outras expressões adverbiais, por exemplo, "soberbamente aclamaram" e "constantemente ele atravessou"; e "Silenciosamente, magistralmente, sorrindo apenas..." (Ibid., p. 1067).

Outro aspecto destacado por Austin (1990, p. 71) é o de que o tom de voz, a cadência e a ênfase "não são fáceis de se reproduzir na linguagem escrita", o que pode ser visto na carta (QUEIROZ, s/d, p. 1064-1067): "Pacheco nunca teve necessidade de deixar sair, para se afirmar e operar fora, aquele imenso talento"; "Pacheco sorria, baixando os olhos sérios por trás dos óculos dourados"; "o seu imenso talento aferrolhado dentro do crânio"; "vendo Pacheco sempre pensabundo, já de óculos, austero nos seus passos, com praxistas gordos debaixo do braço"; "maduríssimo pensar"; e alguns gestos do povo, como "patadas ao chão"; "tão apaixonada e fervente rajada de aclamações"; "instituições [...] todas o apeteceram"; "Portugal [...] repleto de Pacheco.".

O gesto é uma forma de linguagem e dificilmente se desvincula da palavra, pois ambos se enfatizam e se harmonizam. Enfatizam-se uma vez que coexistem, enquanto comunicação; harmonizam-se, enquanto metalinguagem discursiva. Exercem, por isso, dupla função: fática e metalinguística, e redundam em signos linguísticos e icônicos. Pode, ainda, o gesto ser um significante intensificador da palavra: o signo pictórico enfatiza o signo linguístico ou, inversamente, está oximorizado. Dizemos existirem processo oximorísticos e hiperbólicos uma vez que os gestos, em uma leitura sintagmática, são redundantes em relação ao texto implícito, construindo conteúdos hiperbólicos; outrossim, em relação ao texto implícito, produzem conteúdo contraditório, formalizando o oxímoro. Logo, tanto na função oxímora como na hiperbólica, há semias metaforizantes. É um grande elemento caracterizador. Em nível de gestualização estética, o pictórico ajusta-se à palavra ou a desajusta com os contextos situacionais, gerando o grotesco ou, se quisermos, o cômico pela incoerência entre a ação e situação.

Anotamos a seguir alguns fragmentos tradutores do gestual, a maior parte deles referentes a Pacheco, pouco alusivos ao povo, aos deputados e à senhora do Conselheiro. Gestuais referentes a Pacheco: "de pé com o dedo espetado", "e quando emergia de sua concentração, espetando o dedo", "era para lançar alguma ideia geral sobre a Ordem, o Progresso, o Fomento, a Economia", "Pacheco descerrava o braço, tomava com lentidão 
uma nota a lápis", "pensador recluso", "a fronte vergada para o lado como sobre o peso das riquezas interiores", "piscando o olho com finura"; POVO: "e havia amorosos que, serrando os olhos e repinicando um beijo nas pontas apinhadas de dedos, balbuciavam com langor: 'ai que que talento!'”.

Reforçando as considerações de Austin (1962, p. 71) de que o tom de voz, a cadência e a ênfase "não são fáceis de se reproduzir na linguagem escrita", já citado acima, o texto não verbal em conjunção com o verbal produz um terceiro texto alicerçado na linguagem dos gestos e nos gestos da linguagem e somos obrigados a fazer dele não somente uma leitura literal, própria, mas uma literária, transfrástica. Pois os gestos do povo, os gestos de Pacheco não são metalinguagem, mas linguagem icônica, na qual o signo, pela sua globalidade e sugestão, leva o leitor ao transtexto (para além do texto). Os gestos produzem uma linguagem de contrários; são todos eles montados na linha do oximoro. Reais interpretantes culturais corroem a linguagem, e um espaço vazio se cria, pelas anulações bipolares do dizer. Na linguagem dos gestos e nos gestos da linguagem aparece a caricatura de Pacheco agitando, protestando. Nele a caricatura é viva pelo gestual icônico, em Fradique tudo é implícito e só a leitura rítmica revela a sua conturbação oculta pelo consensual. A leitura melódica mostra-nos um anti-texto. É o seu avesso. É o dizer que não foi dito: how to do things with words.

A linguagem, aparentemente um ato ilocutivo, é um ato perlocutivo (AUSTIN, 1990). Através de sua dissecação aparecerá reversa, um verdadeiro ne pas dire (DUCROT, 1972, p. 10): "comunicar seria, antes de tudo, fazer saber, pôr o interlocutor na posse de conhecimentos.”.

As partículas conectivas são outro recurso que destacamos da obra de Austin (1962, p. 71) para quem "Em um nível talvez de maior sutileza, aparece o recurso verbal especial de se usar uma partícula conectiva". Da carta (QUEIROZ, s/d, p. 1064-1068), destacamos os seguintes exemplos: "Todavia, meu caro Sr. Mollinet..."; "e deseja ainda o meu douto amigo saber..."; "mas nunca, nessas situações..."; "e, essa reserva, esse sorrir..."; "e desde que as câmaras se constituíram..."; "Mas nunca, nestas situações, por proveito seu ou urgência do Estado...". Além dos recursos já citados, o sintagma "imenso talento, talento imenso" dá força ao proferimento, que pode ser acompanhado, como já citamos, por gestos. Tais recursos são liberados dos padrões linguísticos. Na carta Ao Sr. E. Mollinet, o sintagma "imenso talento/talento imenso" percorre o texto por aproximadamente 32 vezes, dando importância ao foco da carta e, com isso, gera o ato perlocutivo.

Ainda, a respeito do proferimento, Austin (1962) faz uma distinção entre constatativos e performativos: o fonético, o fático e o rético. $\mathrm{O}$ ato ilocucionário tem a força de dizer algo; o perlocucionário em produzir efeito do dito. Por exemplo: "Eu casualmente conheci Pacheco". Não há sinal de pontuação. Não há pausa. A frase soa melodicamente plana. O ritmo polar é marcado pelos dois ictus: inicial na sílaba "Eu", final na sílaba "che". Essa oração é um monorrema, uma sequência vocálica deslizante, ligada a consoantes fricativas, palatais. Somente em começo de sílabas, as guturais ensurdecem o ritmo vocálico interior. O ictus - eu - inicia o grupo sintático, e se distingue dos demais pela tonicidade, pela função agentiva. Separa-se pelos seus atributos funcionais, e é separado, pelo advérbio em prolepse, do objeto. A linearidade melódica planifica todo o processo frásico. Semanticamente, não há realces. Apenas o ictus sobressai da linha melódica. No espaço significativo, essa construção distancia o sujeito 
do objeto, relevando aquele e apequenando este. Há, podemos dizer, uma semântica rítmica semelhante a um esquema sintático-melódico. O "casualmente" não gerou um proferimento casual.

Na Lecture VIII, Austin (1962) teoriza sobre atos locucionários, ilocucionários e perlocucionários, que recebem o nome de "ato fonético", "ato fático", e "ato rético". O fonético consiste na emissão de ruídos; o fático, no proferimento; e o rético, na criação do sentido, a partir dos quais observamos que a carta ao Sr. E. Mollinet é um ato ilocutório pela sua estrutura textual. Porém, a repetição de "imenso talento" torna-o um ato perlocutivo, como descrito por Austin:

Há um outro sentido [...] em que realizar um ato locucionário, e assim um ato ilocucionário, pode ser também realizar um ato de outro tipo. [...] Chamaremos a realização de um ato deste tipo de realização de um ato perlocucionário ou perlocução. (AUSTIN, 1962, p. 101, tradução de Besma Massad). ${ }^{4}$

Podemos dizer que realizar um ato locucionário é, em geral, eo ipso, realizar um ato ilocucionário, como me proponho denominá-lo. Para determinar que este ato ilocucionário é realizado dessa forma, temos que determinar de que maneira estamos usando a locução, ou seja:

perguntando ou respondendo a uma pergunta;

dando alguma informação, ou garantia ou advertência;

anunciando um veredito ou uma intenção;

pronunciando uma sentença;

marcando um compromisso, fazendo um apelo ou uma crítica;

fazendo uma identificação ou descrição;

e muitos outros casos semelhantes. (Id.) (AUSTIN, 1990, p. 88, tradução de Besma Massad). ${ }^{5}$

Fradique Mendes constrói o Pacheco tal qual o esquema elaborado por Austin (1990), abrindo a possibilidade de leitura do ato ilocucionário e perlocucionário, como segue:

1- É uma pergunta implícita do Sr. Mollinet a uma resposta explícita de Fradique Mendes;

2- Informa quem é Pacheco;

3- A intenção é "imenso talento";

4- Através da ironia constrói o personagem, sentenciando-o: um falso talento;

5- Marca uma crítica implícita ao povo português;

6- Por meio da descrição da trajetória do Pacheco.

\footnotetext{
${ }^{4}$ There is yet further sense [...] in which to perform a locutionary act, and therein an illocutionary act, may also be to perform an act of another kind. [...] We shall can the performance of an act of this kind the performance of a perlocutionary act or perlocution.

${ }^{5}$ To perform a locutionary act is in general, we may say, also and eo ipso to perform an illocutionary act, as I propose to call it. Thus in performing a locutionary act we shall also performing such an act as: asking or answering a question; giving some information or an assurance or a warning; announcing a verdict or an intention; pronouncing sentence; making an appointment or an appeal or a criticism; making an identification or giving a description; and the numerous like.
} 
A narrativa, a partir do advérbio "casualmente", responde a carta ao Sr. Mollinet, na qual o ato perlocucionário explícito, pela repetição do "imenso talento" de Pacheco, deixa, implicitamente, a visão contraditória deste enunciado: Pacheco não tinha nenhum talento. Implicitação essa que salta do ato ilocucionário através do advérbio, da linguagem gestual e da "cultura" de Pacheco. Implicitamente, a crítica ao povo português revela-se através dos verbos performativos calcados nas "carpideiras" e pelo constatativo calcado no gestual.

Por fim, na Lecture XII, "Classe de força ilocucionária", Austin (1962) classifica cinco tipos de proferimentos: veriditivos; exercitivos; comissivos; comportamentais e expositivos. Através do expositivo, os proferimentos se encaixam na argumentação, usando palavras que definem o contexto, o perfil e a ação do personagem marcada pela ironia, como Fradique construiu Pacheco. Ainda, segundo Austin (1962), o veriditivo é um exercício de julgamento, o julgamento do povo português em relação ao "talento" de Pacheco. O exercitivo, uma afirmação do povo português em relação ao "imenso talento" de Pacheco: "Parece que há agora aí um rapaz de imenso talento que se formou, o Pacheco!" (QUEIROZ, s/d, p. 1065). O comissivo, uma declaração, uma intenção do "imenso talento" do Pacheco: o andar, os óculos a faiscar e o discurso óbvio: "o século XIX era um século de progresso e de luz" (Id., Ib.); "que ao lado da liberdade devia sempre coexistir a autoridade!" (Id., Ib.); "um povo sem o curso dos liceus é um povo incompleto" (Id., p. 1066); "o talento verdadeiro só devia conhecer as coisas pela rama" (Id., Ib.). O comportamental, a adoção de uma atitude: "Pacheco descerrava o braço" (Id., Ib.); "Pacheco esborrachou o homem temerário com esta coisa tremenda" (Id., Ib.). O expositivo: o esclarecimento de razões, argumentos e comunicações: "Pacheco não fez durante longos meses absolutamente nada" (Id., Ib.); "Pacheco era entre nós superior e ilustre unicamente porque tinha um imenso talento" (Id., p. 1065).

Imenso Talento. A linguagem do texto da carta ao Sr. Mollinet, aparentemente um ato ilocutivo, é um ato perlocutivo e, através de sua dissecação, aparecerá uma linguagem reversa; um verdadeiro ne pas dire. A superfície não-verbal, com seus brancos semânticos revela significações e os vários protagonistas desse discurso. A multiplicidade de vozes delimita as condições de produção, marcadas pelos vários contextos. Realmente, a cada situação corresponde uma nova condição de produção, uma nova sequência verbal, um novo discurso. A carta ao Sr. E. Mollinet revela-nos uma complexa estrutura discursiva capaz, pelo ato perlocucional (rético), de nos abrir possibilidades de modelar novos conjuntos significativos.

Outro ponto a ser ressaltado, incluso no ato perlocucional, porém consequente do ilocucional, é o trabalho artesão com as categorias gramaticais e com o léxico - que serão as marcas da multiplicidade discursiva.

Essa forma linguística, modelada por tais processos retóricos, levanta dúvida quanto à natureza pragmática do texto de Eça de Queiroz, que tem em vista não só as suas significações internas, mas contextualiza-se com a externa, pois à medida em que o círculo semântico se abre, dilata seu quadro externo significativo e seu processo estruturador se volta para essa amplitude, para essa ilimitação e extrapola o ouvinte: ao Sr. Mollinet juntamente toda nação portuguesa. E a carta passa a ser uma peça verberativa, alcançando mesmo um tom oratório, contra os falsos talentos e valores que obstruem o progresso da nação. O discurso subjacente, por razões do locutor - Fradique - carrega a maior carga significativa e fornece todos os subsídios à total compreensão do texto, 
evitando certas explicitações nem sempre possíveis. Assim sendo, nosso texto crítico seria, no nível do enunciado, um discurso apenas de prestação de contas, por Fradique se dispor a dar informações pedidas pelo Sr. Mollinet.

Entretanto, desde o momento em que a enunciação se desenvolve, a informação se compromete - surge uma contra-informação - com a significação emergente da implicitação e fica polarizado um conceito no interior do discurso de prestação de contas, derivando-o para o discurso de tensão. Isto reforça a nossa visão do tipo não-pragmático do texto de Eça de Queiroz, angulado pelo ato perlocucional - de natureza corrosiva (dizemos corrosiva, pois à natureza do texto irônico é própria tal construção).

Então, com os exemplos citados acima, observamos que os atos perlocutivos criam graus de pluralidade do discurso como resultado das incursões aos códigos retóricos e aos mananciais da língua, cujos achados sintagmáticos são manipulações fradiqueanas, dados perspectivos de seu ponto de vista sobre o referente Pacheco.

Esta amostragem documenta a superfície discursiva e o processo de produção como decorrente da condição de produção dos protagonistas do discurso. O texto, assim estruturado, conduz o analista a ver nele uma intencionalidade deliberativa para criar situações contextuais que extrapolam o nível do enunciado, salientando a implicitação enunciativa. Não se nega que tal processo resulta de manobras estilísticas, de vez que se observa na manipulação do advérbio: "casualmente", "absolutamente", "amargamente", "soberbamente", "silenciosamente", "magistralmente", "unicamente", com o propósito de indiciar a linguagem para a implicitação como para os gestos que ela mesma pratica. Tal superfície discursiva se constrói com os gestos da linguagem, enquanto muitas vezes na enunciação se encontra a linguagem de gestos.

\section{A queda da máscara de Pacheco}

A leitura da carta causou-nos alguma perplexidade pela sua dialética, superfície discursiva e condições de produção. Se por uma leitura da enunciação explícita nos chega a afirmação do imenso talento - que é demonstrado pelo traçado do enunciado - uma leitura de enunciações nos demonstra exatamente o inverso. Temos uma dialética contraditória na qual a tese é a afirmação (o que está explícito), a antítese é a negação (o que está implícito) e a síntese é feita pelo leitor após ler o que está escrito e entender o que está dito. Parece-nos, pois, termos dois discursos: o superficial e o profundo; além de uma pluralidade discursiva emanada de sua superfície.

A carta Ao Sr. E. Mollinet é uma síntese da carreira de Pacheco - surgida de seu imenso talento. Entretanto, alguns pontos culminantes e geradores de outros são preciosamente detalhados por Fradique, contudo, essa postura de close-up não retarda o relato, não o obstrui, antes o sumário explicita e antecipa as atitudes e o comportamento dos protagonistas. O compacto que Fradique fez sobre o talento de Pacheco edifica-se por sobre etapas basilares e sua carreira - causas explícitas e efeitos implícitos. Só em um dos períodos finais reúne-os claramente: "de resto necessitavam insubstituivelmente um do outro e se completavam” (QUEIROZ, s/d, p. 1067) - o talento de Pacheco e Portugal.

Assim, este texto de Eça é um discurso apodítico, pois Fradique parte de um axioma incontestável para o povo português: o talento de Pacheco - e demonstra toda sua evidência, segundo o ponto de vista da nação. Porém, o protagonista Fradique ao tentar comprovar a evidência desse axioma, para confirmá-lo, não a encontra. $\mathrm{O}$ discurso 
demonstrativo não esbarra com o verificativo, segundo o ponto de vista de Fradique; mas se conjugam segundo o povo. Infere-se, pois, que dois pontos de vista regem o texto: o do povo e o de Fradique; antagônicos e diferenciados. E isso se verifica tanto no ato ilocucionário como no perlocucionário da linguagem. Os graus do discurso e sua pluralidade discursiva surgem do enunciado.

Fradique apresenta um momento problemático da sociedade portuguesa pela estagnação cultural, pelo esvaziamento de valores políticos e morais. Há um choque ideológico e ele se reflete na organização discursiva. É o momento do impacto: destruir para construir. A estruturação espelha este conflito, esta contradição pela ironia, pelo cômico, quando a máscara cai.

A partir deste enfoque, pelas várias leituras possíveis do texto de Eça, se institui e se demonstra a existência de um outro texto, ainda que descoberto por caminhos diferentes. Assim, todas as análises levam o leitor para um segundo texto, construído e caracterizado pela ênfase, antítese, contradição, apoditismo, silogismo, implicitação, ne pas dire, sous entendu (oximoro), ironia. Este segundo texto, sempre presente no discurso da ironia, afirmava que Pacheco, o grande ídolo, é um ídolo falso (o zero); é um homem estratificado por sua sociedade e seu tempo, e também um produto dela. Um mito criado pela coletividade, mito esse presente no primeiro texto, contudo desmistificado no segundo.

Confrontando o primeiro discurso (texto literal de Fradique) com o segundo (texto metalinguístico, nascido do ato perlocutivo, do sous entendu) temos o contraditório, as tensões.

Toda a análise feita evidencia a existência de dois níveis que o leitor qualificado descobre, analisa, coteja e demonstra, chegando ao núcleo do texto por comprovações diversas, o que não invalida a chegada, desde que a subjetividade - o impressionismo não foi arma, nem interferente. Foi-nos dado observar, porém, o acréscimo que cada elemento enfocado somava à valorização e à compreensão do texto.

A dualidade discursiva, a tensão, o tom oratório em texto pragmático, os vários protagonistas, a interlocução, saltaram à vista em todo o processo de análise. Em alguns pontos, a evidência foi maior do que em outras, de modo que as contribuições de Austin (1962) e Searle (1969) foram seminais para enriquecer as descobertas reveladas no texto de Eça de Queiroz por meio da pesquisa, da investigação e da recepção - pelo ato de leitura. Com isso, o texto não se atrofiou, não se estagnou na linha da temporalidade. Agigantou-se pelas suas próprias qualidades imanentes e orgânicas. $\mathrm{O}$ texto disse $\mathrm{e}$ permitiu que nós, leitores, igualmente, o disséssemos.

\section{Considerações finais}

"Eu casualmente conheci Pacheco" enunciado iniciador da resposta de Fradique a Mollinet uma vez que "casualmente" é o marco discursivo da carta. Se tal enunciado inicia a narrativa resposta de Fradique a Mollinet, o parágrafo final dessa carta fecha a informação sobre Pacheco:

Meses depois da morte de Pacheco encontrei a sua viúva, em Sintra, [...] Mas quando, comovido, aludi ao imenso talento de Pacheco, a viúva de Pacheco ergueu, num brusco 
espanto, um apiedado sorriso arregaçou-lhe os cantos da boca pálida. (QUEIROZ, s/d, p. 1068).

O tempo decorrido entre estas duas citações é a carta resposta que será enviada ao senhor Mollinet. Entre o dizer "casualmente" e o fazer "aludi" se estabelece uma relação oximórica. O texto que a construiu pode ser lido e estudado através de Austin e Searle, lembrando que "ato de fala" é a palavra em ação, o que foi visto através do texto produzido. Ante a pluralidade do discurso da enunciação, da implicitação o leitor teve de achar o seu fio de Ariadne e substituir o enunciado "casualmente conheci Pacheco" por "verdadeiramente conheci Pacheco", após desmanchar os pontos e as laçadas do texto.

O fio de Ariadne passou pelas leituras de Austin $(1962,1990)$, pelo "ato de fala" de Searle (1969), pela langue de Saussure (1969) e também pela parole. No enunciado de Searle, texto é uma mensagem produzida ou emitida; para compreendê-lo e vê-lo exige do leitor uma incursão aos volteios da linguagem. Acontece que nem sempre o caminho é linear, há meandros, curvas que impedem uma só versão, uma só decoupage; então, para ler apropriamo-nos de How to things with words, de Austin (1962) e de atos (funções, movimentos) de fala (linguagem, palavra), de Searle (1969): nos quais estão os verbos performativos e constatativos e a força ilocucionária, como emitir um proferimento performativo, por meio dos quais há o recurso comum do uso do modo imperativo; do tom de voz; de advérbios e expressões adverbiais; de partículas conectivas; elementos que acompanham o proferimento como gestos: piscar de olhos, dar de ombro, franzir o cenho, etc. Todos esses recursos encontram-se na carta Ao Sr. E. Mollinet, por nós registrados, principalmente na gestualidade de Pacheco, do povo e dos deputados.

Lembremo-nos de "A Fonte" (DUCHAMP, 1917), um vaso sanitário, um objeto; o mesmo vaso numa loja de material de construção tem uma função e, no museu, é o ready made "A Fonte". O significante, a forma, é sempre a mesma, em outro contexto o significado muda e opera outros significados. Então, a palavra não é uma mera representação, é significado com possibilidades geradoras. Por todas essas dificuldades, haja as pedras de Drummond, são tropeços linguísticos.

A carta Ao Sr. E. Mollinet é uma resposta de Fradique, é uma chasse linguística exigindo do decouper conhecimento de linguagem, de langue e de parole.

Fradique, perfilado na "Correspondência" como personagem de Eça de Queiroz, é português, culto, filósofo, de posição social elevada, rico, original, viajado, quase um sábio, enfim. Sr. Mollinet, pincelado brevemente por Fradique, diretor da Revista de Biografia e História, douto. Pacheco, objeto de referência do Sr. Mollinet, é um português falecido recentemente, chorado pela nação portuguesa, idolatrado pelo povo - conhecido casual de Fradique. Todos pertencem a um mesmo contexto econômico-social, com um desnivelamento ideológico de Pacheco. Estas igualdades e diferenças atuam sobre o jogo do discurso por meio de estratégias e imagens, atos de linguagem, imagens e atos. Nesse jogo discursivo, aos poucos, a máscara é retirada pelo leitor no ato da leitura: "Eu casualmente conheci o Pacheco" (QUEIROZ, s/d, p. 1064). O leitor que caminhe pela estrutura sintática e tropece com o advérbio "casualmente". Aí começam os primeiros traços da máscara de Pacheco, tão bem estruturada quanto How to do things with words.

As mãos, o teclado do computador foram as agulhas que construíram os pontos deste texto, sob os olhares de Austin e Searle. Citando Searle $(1969$, p. 16) mais uma vez, "Tomar o texto como uma mensagem é tomá-lo como um texto produzido ou emitido.". 


\section{REFERÊNCIAS}

AUSTIN, J. L. How to do things with words. Oxford: At The Clarendon Press, 1962.

Quando dizer é fazer. Tradução de Danilo Marcondes de Souza Filho. Porto Alegre: Artes Médicas, 1990.

DUCROT, O. Dire et ne pas dire. Paris: Hermann, 1972.

QUEIROZ, E. Obras Completas. v. II. Porto: Lello \& Irmão Editores, s/d.

SAUSSURE, F. de. Curso de linguistica geral. São Paulo: Cultrix, 1969.

SEARLE, J. R. Speech Acts: an essay in the philosophy of language. Cambridge: At The University Press, 1969.

SOUZA FILHO, D. M. A filosofia da linguagem de J. L. Austin. In: AUSTIN, J. L. Quando dizer é fazer. Tradução de Danilo Marcondes de Souza Filho. Porto Alegre: Artes Médicas, 1990.

Recebido em: 19/09/2017

Aprovado em: 19/06/2018 


\section{ANEXO}

AO SR. E. MOLLINET

Director da Revista de Biografia e de História

Paris, Setembro.

Meu Caro Sr. Mollinet. - Encontrei ontem à noite, ao voltar de Fontainebleau, a carta em que o meu douto amigo, em nome e no interesse da Revista de Biografia e de História, me pergunta quem é este meu compatriota Pacheco (José Joaquim Alves Pacheco), cuja morte está sendo tão vasta e amargamente carpida nos jornais de Portugal. E deseja ainda o meu amigo saber que obras, ou que fundações, ou que livros, ou que ideias, ou que acréscimo na civilização portuguesa deixou esse Pacheco, seguido ao túmulo por tão sonoras, reverentes lágrimas.

Eu casualmente conheci Pacheco. Tenho presente, como num resumo, a sua figura e a sua vida. Pacheco não deu ao seu País nem uma obra, nem uma fundação, nem um livro, nem uma ideia. Pacheco era entre nós superior e ilustre unicamente porque tinha um imenso talento. Todavia, meu caro Sr. Mollinet, este talento, que duas gerações tão soberbamente aclamaram, nunca deu, da sua força, uma manifestação positiva, expressa, visível! O talento imenso de Pacheco ficou sempre calado, recolhido, nas profundidades de Pacheco! Constantemente ele atravessou a vida por sobre eminências sociais: Deputado, Director-geral, Ministro, Governador de bancos, Conselheiro de Estado, Par, Presidente do Conselho - Pacheco tudo foi, tudo teve, neste País que, de longe e a seus pés, o contemplava, assombrado do seu imenso talento. Mas nunca, nestas situações, por proveito seu ou urgência do Estado, Pacheco teve necessidade de deixar sair, para se afirmar e operar fora, aquele imenso talento que lá dentro o sufocava. Quando os amigos, os partidos, os jornais, as repartições, os corpos colectivos, a massa compacta da Nação murmurando em redor de Pacheco «que imenso talento!» o convidavam a alargar o seu domínio e a sua fortuna - Pacheco sorria, baixando os olhos sérios por trás dos óculos dourados, e seguia, sempre para cima, sempre para mais alto, através das instituições, com o seu imenso talento aferrolhado dentro do crânio, como no cofre dum avaro. E esta reserva, este sorrir, este lampejar dos óculos, bastavam ao País, que neles sentia e saboreava a resplandecente evidência do talento de Pacheco.

Este talento nasceu em Coimbra, na aula de direito natural, na manhã em que Pacheco, desdenhando a Sebenta, assegurou que «o século XIX era um século de progresso e de luz». O curso começou logo a pressentir e a afirmar, nos cafés da Feira, que havia muito talento em Pacheco: e esta admiração cada dia crescente do curso, comunicando-se, como todos os movimentos religiosos, das multidões impressionáveis às classes raciocinadoras, dos rapazes aos lentes, levou facilmente Pacheco a um prémio no fim do ano. A fama desse talento alastrou então por toda a Academia - que, vendo Pacheco sempre pensabundo, já de óculos, austero nos seus passos, com praxistas gordos debaixo do braço, percebia ali um grande espírito que se concentra e se retesa todo em força íntima. Esta geração académica, ao dispersar, levou pelo País, até os mais sertanejos burgos, a notícia do imenso talento de Pacheco. E lá em escuras boticas de Trás-osMontes, em lojas palreiras de barbeiros do Algarve, se dizia, com respeito, com esperança: - «Parece que há agora aí um rapaz de imenso talento que se formou, o Pacheco!». 
Pacheco estava maduro para a representação nacional. Veio ao seu seio — trazido por um Governo (não recordo qual) que conseguira, com dispêndios e manhas, apoderarse do precioso talento de Pacheco. Logo na estrelada noite de Dezembro em que ele, em Lisboa, foi ao Martinho tomar chá e torradas, se sussurrou pelas mesas, com curiosidade: — «É o Pacheco, rapaz de imenso talento!». E desde que as Câmaras se constituíram, todos os olhares, os do governo e os da oposição, se começaram a voltar com insistência, quase com ansiedade, para Pacheco, que, na ponta duma bancada, conservava a sua atitude de pensador recluso, os braços cruzados sobre o colete de veludo, a fronte vergada para o lado como sobo peso das riquezas interiores, e os óculos a faiscar... Finalmente uma tarde, na discussão da resposta ao discurso da Coroa, Pacheco teve um movimento como para atalhar um padre zarolho que arengava sobre a «liberdade». O sacerdote imediatamente estacou com deferência; os taquígrafos apuravam vorazmente a orelha: e toda a câmara cessou o seu desafogado sussurro, para que, num silêncio condignamente majestoso, se pudesse pela vez primeira produzir o imenso talento de Pacheco. No entanto Pacheco não prodigalizou desde logo os seus tesouros. De pé, com o dedo espetado (jeito que foi sempre muito seu), Pacheco afirmou num tom que traia a segurança do pensar e do saber íntimo: - «que ao lado da liberdade devia sempre coexistir a autoridade!». Era pouco, decerto: - mas a câmara compreendeu bem que, sob aquele curto resumo, havia um mundo, todo um formidável mundo, de ideias sólidas. Não volveu a falar durante meses - mas o seu talento inspirava tanto mais respeito, quanto mais invisível e inacessível se conservava lá dentro, no fundo, no rico e povoado fundo do seu ser. O único recurso que restou então aos devotos desse imenso talento (que já os tinha, incontáveis), foi contemplar a testa de Pacheco - como se olha para o céu pela certeza que Deus está por trás, dispondo. A testa de Pacheco oferecia uma superfície escanteada, larga e lustrosa. E muitas vezes, junto dele, Conselheiros e Directores gerais balbuciavam maravilhados: - «Nem é necessário mais! Basta ver aquela testa!».

Pacheco pertenceu logo às principais comissões parlamentares. Nunca porém acedeu a relatar um projecto, desdenhoso das especialidades. Apenas às vezes, em silêncio, tomava uma nota lenta. E quando emergia da sua concentração, espetando o dedo, era para lançar alguma ideia geral sobre a Ordem, o Progresso, o Fomento, a Economia. Havia aqui a evidente atitude dum imenso talento que (como segredavam os seus amigos, piscando o olho com finura) «está à espera, lá em cima, a pairar». Pacheco mesmo, de resto, ensinava (esboçando, com a mão gorda, o voar superior duma asa por sobre o arvoredo copado) que o «talento verdadeiro só devia conhecer as coisas pela rama».

Este imenso talento não podia deixar de socorrer os conselhos da Coroa. Pacheco, numa recomposição ministerial (provocada por uma roubalheira), foi Ministro: e imediatamente se percebeu que maciça consolidação viera dar ao Poder o imenso talento de Pacheco. Na sua pasta (que era a da Marinha), Pacheco não fez durante os longos meses de gerência «absolutamente nada», como insinuaram três ou quatro espíritos amargos e estreitamente positivos. Mas pela primeira vez, dentro deste regime, a Nação deixou de curtir inquietações e dúvidas sobre o nosso Império Colonial. Por quê? Porque sentia que, finalmente, os interesses supremos desse Império estavam confiados a um imenso talento, ao talento imenso de Pacheco.

Nas cadeiras do governo, Pacheco rarissimamente surdia do seu silêncio repleto e fecundo. Às vezes, porém, quando a oposição se tornava clamorosa, Pacheco descerrava o braço, tomava com lentidão uma nota a lápis: — e esta nota, traçada com saber e 
maduríssimo pensar, bastava para perturbar, acuar a oposição. É que o imenso talento de Pacheco terminara por inspirar, nas câmaras, nas comissões, nos centros, um terror disciplinar! Ai desse sobre quem viesse a desabar, com cólera, aquele talento imenso! Certa lhe seria a humilhação irresgatável! Assim dolorosissimamente o experimentou o pedagogista, que um dia se arrojou a acusar o Sr. Ministro do Reino (Pacheco dirigia então o Reino) de descurar a Instrução do País! Nenhuma incriminação podia ser mais sensível àquele imenso espírito que, na sua frase lapidária e suculenta, ensinara que «um povo sem o curso dos liceus é um povo incompleto». Espetando o dedo (jeito sempre tão seu) Pacheco esborrachou o homem temerário com esta coisa tremenda: - «Ao ilustre deputado que me censura só tenho a dizer que enquanto, sobre questões de Instrução Pública, S. Ex.a, aí nessas bancadas, faz berreiro, eu, aqui nesta cadeira, faço luz!» — Eu estava lá, nesse esplêndido momento, na galeria. E não me recordo de ter jamais ouvido, numa assembléia humana, uma tão apaixonada e fervente rajada de aclamações! Creio que foi daí a dias que Pacheco recebeu a grã-cruz da Ordem de Sant' Iago.

O imenso talento de Pacheco pouco a pouco se tornava um credo nacional. Vendo que inabalável apoio esse imenso talento dava às instituições que servia, todas o apeteceram. Pacheco começou a ser um Director universal de Companhias e de Bancos. Cobiçado pela Coroa, penetrou no Conselho de Estado. O seu partido reclamou avidamente que Pacheco fosse seu Chefe. Mas os outros partidos cada dia se socorriam, com submissa reverência, do seu imenso talento. Em Pacheco pouco a pouco se concentrava a Nação.

À maneira que ele assim envelhecia, e crescia em influência e dignidades, a admiração pelo seu imenso talento chegou a tomar no País certas formas de expressão só próprias da religião e do amor. Quando ele foi Presidente do Conselho, havia devotos que espalmavam a mão no peito com unção, reviravam o branco do olho ao Céu, para murmurar piamente: - «Que talento!» E havia amorosos que, cerrando os olhos e repenicando um beijo nas pontas apinhadas dos dedos, balbuciavam com langor: — «Ai! que talento!» E, para que o esconder? Outros havia, a quem aquele imenso talento amargamente irritava, como um excessivo e desproporcional privilégio. A esses ouvi eu bradar com furor, atirando patadas ao chão: - «Irra, que é ter talento de mais!» Pacheco no entanto já não falava. Sorria apenas. A testa cada vez se lhe tornava mais vasta.

Não relembrarei a sua incomparável carreira. Basta que o meu caro Sr. Mollinet percorra os nossos anais. Em todas as instituições, reformas, fundações, obras, encontrará o cunho de Pacheco. Portugal todo, moral e socialmente, está repleto de Pacheco. Foi tudo, teve tudo. Decerto, o seu talento era imenso! Mas imenso se mostrou o reconhecimento da sua Pátria! Pacheco e Portugal, de resto, necessitavam insubstituivelmente um do outro, e ajustadissimamente se completavam. Sem Portugal - Pacheco não teria sido o que foi entre os homens: mas sem Pacheco - Portugal não seria o que é entre as nações!

A sua velhice ofereceu um carácter augusto. Perdera o cabelo radicalmente. Todo ele era testa. E mais que nunca revelava o seu imenso talento - mesmo nas mínimas coisas. Muito bem me lembro da noite (sendo ele Presidente do Conselho) em que, na sala da Condessa de Arrodes, alguém, com fervor, apeteceu conhecer o que S. Ex.a pensava de Canovas del Castillo. Silenciosamente, magistralmente, sorrindo apenas, S. Ex.a deu com a mão grave, de leve, um corte horizontal no ar. E foi em torno um murmúrio de admiração, lento e maravilhado. Naquele gesto quantas coisas subtis, 
fundamente pensadas! Eu por mim, depois de muito esgaravatar, interpretei-o deste modo: - «medíocre, meia-altura, o Sr. Canovas!» Porque, note o meu caro Sr. Mollinet como aquele talento, sendo tão vasto - era ao mesmo tempo tão fino!

Rebentou; - quero dizer, S. Ex.a morreu, quase repentinamente, sem sofrimento, no começo deste duro Inverno. Ia ser justamente criado Marquês de Pacheco. Toda a Nação o chorou com infinita dor. Jaz no alto de S. João, sob um mausoléu, onde por sugestão do Sr. conselheiro Acácio (em carta ao Diário de Notícias) foi esculpida uma figura de Portugal chorando o Génio.

Meses depois da morte de Pacheco, encontrei a sua viúva, em Sintra, na casa do Dr. Videira. É uma mulher (asseguram amigos meus) de excelente inteligência e bondade. Cumprindo um dever de português, lamentei, diante da ilustre e afável senhora, a perda irreparável que era sua e da Pátria. Mas quando, comovido, aludi ao imenso talento de Pacheco, a viúva de Pacheco ergueu, num brusco espanto, os olhos que conservara baixos — e um fugidio, triste, quase apiedado sorriso arregaçou-lhe os cantos da boca pálida... Eterno desacordo dos destinos humanos! Aquela mediana senhora nunca compreendera aquele imenso talento! Creia-me, meu caro Sr. Mollinet, seu dedicado. — FRADIQUE.

QUEIROZ, Eça. A Correspondência de Fradique Mendes - VIII Ao Sr. E. Mollinet. Obras Completas. v. II. Porto: Lello \& Irmão Editores, s/d. p. 1064-1068. 